
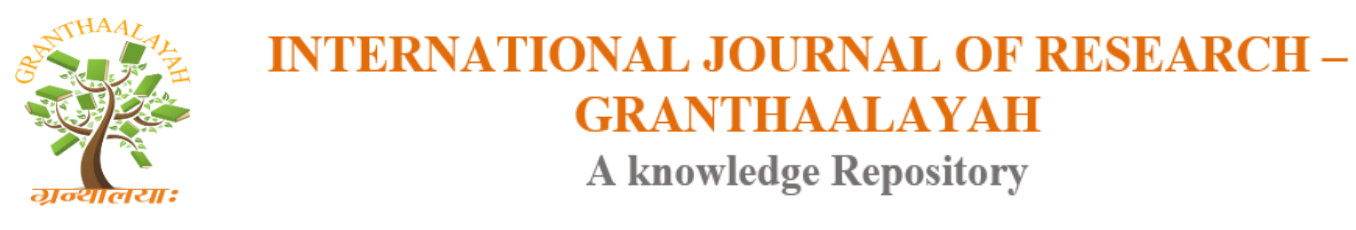

Social

\title{
HEALTH LITERACY: AN OVERVIEW OF THE MEDICAL SECRETARIAL TRAINING IN TURKEY
}

\author{
Perihan Şenel Tekin *1 \\ ${ }^{* 1}$ Vocational School of Health, Ankara University, Turkey
}

\begin{abstract}
Background: Health literacy has a measure of capacity to access, understand, assess, and apply health information in individuals' decision-making processes to maintain and improve life-quality quality of life. Research is a descriptive study aiming to determine the health literacy level of medical secretary' students who are health professionals and the influencing factors of health literacy in the future.

Method: The research was conducted between April 30 and June 1, 2018, and the study group consisted of 55 medical secretary students who study in Ankara University Vocational School of Health in Turkey. The participants were given the questionnaire which was composed of 3 sections (socio-demographic information, health status, and the Health Literacy Survey-European Union/HLS-EU scale) and 70 questions used for data collection purposes.

Results: The average age of the group was $21.4 \pm 4.1$. The average score of participants' general health literacy index was calculated as 33.9 $\pm 7.42(n=55)$. Approximately $70 \%$ of participants $(\mathrm{n}=55)$ were found to have adequate health literacy.

Conclusions: It is very important that the medical secretaries working as secretarial and patient orientation personnel in the health sector are health literate in terms of their own health and health service quality. Health literacy can't be considered independent of the general literacy level. Hence, in the lifelong learning process, individuals need to be supported in school and work life.
\end{abstract}

Keywords: Health Education; Health Literacy; Healthcare Management; Healthcare Professionals; Medical Secretary.

Cite This Article: Perihan Şenel Tekin. (2018). "HEALTH LITERACY: AN OVERVIEW OF THE MEDICAL SECRETARIAL TRAINING IN TURKEY.” International Journal of Research - Granthaalayah, 6(9), 79-92. https://doi.org/10.5281/zenodo.1435228.

\section{Introduction}

Nowadays, the health system has finally become the more complex structure for both supply and demand. Within this complex structure, health literacy and health communication in the process of improving the health of the community is now much more important than the old one. The scope of the health literacy should be expanded to include the ability to access, understand, evaluate, and communicate information on the social determinants of health (CSDH, 2008). Health literacy is 
an important determinant of health, and the concept that has entered our life 45 years ago just became more visible in the last decade (Rudd, 2015a) and is constantly evolving (Nutbeam, 2008; Rudd, 2015a).

The health service providers, acting on the assumption that the beneficiaries of the health service are conscious individuals, considering that patients and their relatives are health literate. However, the facts do not always coincide with this assumption (Kripalani et al., 2010; Kutner, Greenburg, Jin, \& Paulsen, 2006; Mitchell, Sadikova, Jack, \& Paasche-Orlow, 2012; Parker, Baker, Williams, \& Nurss, 1995; Sørensen et al., 2015; Turkoglu et al., 2018; von Wagner, Knight, Steptoe, \& Wardle, 2007; Wallston et al., 2014; Yuen, Knight, Ricciardelli, \& Burney, 2018). Such that the complexity of the diagnostic processes, the increase in the addition of medical information every day, the level and the differences of general education and culture of the people, the increase in the number of migrants and the accompanying problems, age-related physical and cognitive problems, understanding, listening, learning and remembering skills, and other psychosocial factors are negatively affecting the level of health literacy, therefore, health care delivery is facing even more difficult situations (Kripalani et al., 2010; Mitchell et al., 2012; Parker et al., 1995; von Wagner et al., 2007; Wallston et al., 2014; Yuen et al., 2018).

With the differences across Europe, the prevalence of inadequate and problematic health literacy is quite high, (Sørensen et al., 2015) and it is a big question at a time when it will not be seen as the problem of minority groups alone (Consortium, 2012). According to the United States data, about one in four of the population have limited health literacy and are therefore forced to use the health system, make health decisions, and receive quality health care (Wallston et al., 2014). Less than half of the people in Australia have minimal literacy and mathematical knowledge to perform the daily basic functions (Adams et al., 2009; Bush, Boyle, \& Ostini, 2010). Given that health literacy is often at a lower level than literacy and numeracy, it can be understood how serious problem it is, for the communities and the parts of the healthcare systems.

Health literacy is considered to be an important factor in improving the individual's health level (Berkman, Sheridan, Donahue, Halpern, \& Crotty, 2011; Raynor, 2012; von Wagner et al., 2007). Such that, poor literacy skills are associated with the worse health outcomes (Berkman, Sheridan, Donahue, Halpern, \& Crotty, 2011) and the poorer health care utilization and predict unmet medical outcomes (Rudd, 2015b). The better health literacy enables health-friendly environments, efficient policies, effective promotional efforts, the better self-care with the fewer risks, and results in the improved health care outcomes and the lower health costs (İlgün, Turaç, \& Orak, 2015; Raynor, 2012).

Health literacy can be described as the combination of the knowledge, attitudes, skills and networks that individuals, families and communities need to manage their health (Sørensen et al., 2012). Its adequacy helps to protect people's health, to manage small diseases, to access health care and health services, to follow agreed treatments and personal care routines, and to support a healthy society (Von Wagner, Steptoe, Wolf, \& Wardle, 2009).

Achieving these goals requires a health understanding and factors that affect it requires the understanding of health care services and the motivation to play an active role in managing how they work and their health. All health-related tasks which maintaining to protect health depend on 
the degree of health literacy (Lloyd, Thomas, Powell-Davies, Osten, \& Harris, 2018; PaascheOrlow \& Wolf, 2007).

The concept of health literacy, which is considered to be important in many aspects, from production to management, quality (Kahraman, Karagöz, Yalman, \& Yusuf, 2018) to cost of health care (Rasu, Bawa, Suminski, Snella, \& Warady, 2015), is defined as the capacity to acquire, process, understand and use health knowledge in its most general form (İlgün et al., 2015; Kutner et al., 2006; Nutbeam, 2008; Parker et al., 1995; Raynor, 2012; Rudd, 2007, 2015a, 2015b; Rudd, Moeykens, \& Colton, 1999). However, the definition of health literacy is becoming increasingly complex with many skill categories and practices within the context of being "literate" in the relevant sense (Batterham, Hawkins, Collins, Buchbinder, \& Osborne, 2016; Berkman, Davis, \& McCormack, 2010; Haun, Valerio, McCormack, Sørensen, \& Paasche-Orlow, 2014; Lloyd et al., 2018; Rudd, 2015a; Sørensen et al., 2015; Sørensen et al., 2013).

According to the index developed by the HLS-EU Consortium, health literacy is related to general literacy. Health literacy has a measure of capacity to access, understand, assess and apply health information in individuals' decision-making processes to maintain and improve lifelong quality of life (Durusu-Tanriöver, 2014).

Over the past decade, more than fifty tools have been developed (Haun et al., 2014) and numerous studies have been conducted to measure individuals' health literacy skills (Baker, 2006; Duong et al., 2017; Durusu-Tanriöver, 2014; Haun et al., 2014; İlgün et al., 2015; Kirsch, 1993; Kutner et al., 2007; Kutner et al., 2006; Nutbeam, 2008; Parker et al., 1995; Raynor, 2012; Rudd, 2007; Sørensen et al., 2015). Despite the numerous researches on the sickness dimension of health literacy, however, there are few researches on many topics, especially health care, health care administration and policy, medicine, nursing, dentistry, pharmacy services that affect health (Coleman, 2011; Deniz, Öztaş, \& Akbaba, 2018; Güven, Bulut, \& Öztürk, 2018; Rudd, 2015b). For example, issues such as how health professionals can improve the literacy skills of the public, the responsibilities of the education sector, the communication skills of specialists and more attention to facilitating or hindering factors in the health context are pointing to gaps in health literacy writing for researchers (Rudd, 2015a). Moreover, individual contributions of health professionals to health literacy levels and also other individuals' contribution to these need to be investigated as well.

The researches have an important role in bringing about healthcare-related problems and solutions to be developed for healthy individuals and communities, and for a sustainable health system. In this context, the aim of the research is to determine the health literacy levels of the medical secretary students who are both health worker and an individual, as well as health professionals and the influencing factors of health literacy in the future.

\section{Materials and Methods}

A descriptive cross-sectional and quantitative research design was used to determine the health level and the influencing factors of the medical secretary students who are a future health professional. The study group consisted of the students $(n=84)$ who study at Ankara University Vocational School of Health Services, the Medical Secretary programme in 2018. The study 
needed no further ethical approval. The students were informed of the research and questionnaire was distributed to 55 volunteer students (\%65.5).

The questionnaire was used as the data collection tool. Surveys were shared online with Google docs via email between April 30 and June 1, 2018. The participant's responses to the questionnaire were composed of 3 sections of 70 questions used for data collection purposes and completed in approximately 15 minutes. In the first part of the questionnaire, there were 14 questions about socio-demographic information, there were 9 questions about health status in the second part, while there were questions about health literacy with 47 questions in the third section of the questionnaire.

The sections of the questionnaire and the number of questions/statements included are given below:

- Socio-demographic characteristics (14 questions)

- Health status (9 questions)

- Health Literacy Scale (47 questions)

The first part of the questionnaire consists of the 14 questions including participants' sociodemographic characteristics. The socio-demographic information consists of gender, age, marital, status, education level, height, weight, education, family structure, living characteristics, income, book and newspaper reading habits. In the health status section of the questionnaire diet, exercise, tea, coffee, and water consumption, smoking, alcohol usage, health insurance and individual health perception of the participants were recorded.

In the third part of the questionnaire, Turkey Health Literacy questionnaire (HLS-T-Q) was used as a data collection tool. The HLS-T-Q is translated into Turkish for the first time by Durusu et al, the validity and reliability study was conducted for the European Health Literacy Questionnaire (HLS-EU-Q) and then was applied to 4924 people (Durusu-Tanrı̈̈ver, 2014). The questionnaire consists of 47 questions showing the four-point Likert type (very easy, easy, hard, very difficult) scale feature. The questionnaire was first developed as the HLS-EU-Q for Consortium of European Health Literacy Surveys and applied to 8102 individuals over 15 years of age from 8 European countries such as Germany, Netherlands, Austria, Spain, Italy, Greece, Bulgaria and Poland. The related report was published in 2012 (Sørensen et al., 2015). This scale is based on the perception of each person by how much 'easy' or 'difficult' behaviour is indicated in each question. Subindices based on the average values of the health literacy parameters were formed within the HLSEU concept. The scale was analyzed within a matrix of healthcare literacy, information access, comprehension, evaluation, and application in the areas of health care, disease prevention and health improvement (Table 1).

Table 1: Health literacy-EU Matrix Questionnaires

\begin{tabular}{|l|l|l|l|l|l|}
\hline Health Literacy & Access & Comprehension & Evaluation & Application & Total \\
\hline Health care & $1-4$ & $5-8$ & $9-12$ & $13-16$ & $1-16$ \\
\hline Disease prevention & $17-20$ & $21-23$ & $24-28$ & $29-31$ & $17-31$ \\
\hline Health promotion & $32-36$ & $37-40$ & $41-43$ & $44-47$ & $32-47$ \\
\hline
\end{tabular}


In the analysis of the data, statistical package program (IBM SPSS Statistics for Windows, Version 25.0) was used. Normal distribution suitability of variables was analyzed by Shapiro-Wilk test. The data are normally distributed (Tabachnick \& Fidell, 2007). For the descriptive statistics in data analysis, mean and standard deviation in continuous variables and number and percentage values in categorical variables were used. The average score for the index of health literacy and general and sub-index scores was calculated by comparison with the results of the EU and Turkey. In order to be able to use a questionnaire for index score calculation, at least $80 \%$ of the number of questions must be answered in each index and sub-index. In this study, it was observed that all participants answered at least $80 \%$ for index calculations and all of the questionnaires were evaluated. Indices are standardized as specified in form so that ' 0 ' shows the lowest health literacy, ' 50 ' the highest health literacy on a scale of ' 0 ' to ' 50 '. To allow convenient calculations with indices and to simplify comparisons, four scales (general health literacy, health care, disease prevention, health promotion) were standardized on a metric between 0 and 50, using the following formula:

$\mathrm{I}=(\mathrm{X}-1) *(50 / 3)$

' $\mathrm{I}$ ' is the specific index calculated.

' $\mathrm{X}$ ' is the mean of all participating items for each Individual.

' 1 ' is the minimal possible value of the mean (leads to a minimum value of the index of 0 ).

' 3 ' is the range of the mean.

' 50 ' is the chosen maximum value of the new metric.

Health literacy level, with the aim to make them comparable with Turkey and the European study, were grouped into four categories. Using the scores on the 47 items measuring health literacy a comprehensive general index of health literacy was constructed. For that purpose, mean-based item raw scores were computed for respondents who gave valid answers to at least $80 \%$ of all health literacy questions $(n=55)$. To simplify comparisons between scores on the general health literacy index and its various sub-index, all scores were transformed to a unified metric with a minimum of ' 0 ' and a maximum of ' 50 ', where ' 0 ' represents the 'least possible' and ' 50 ' represents the 'best possible' health literacy score. The resulting four levels were 'inadequate' ( 0 25), 'problematic' (>25-33), 'sufficient' (>33-42) and 'excellent' (>42-50) health literacy. In some analysis, it was used the 'inadequate' and 'problematic' levels were combined to a single level, called 'limited health literacy' (0-33); 'sufficient' and 'excellent' levels were combined to a single level called 'sufficient health literacy' (34-50).

Internal consistency was assessed by determining the Cronbach's alpha coefficient for the reliability of the health literacy indices. As all index internal consistency values are above 0.80, they are considered highly reliable (Table 2) (Cortina, 1993).

Table 2: Internal reliability coefficients of the health literacy and sub-indices.

\begin{tabular}{|l|l|}
\hline Health Literacy & Cronbach alpha \\
\hline General Health Literacy & 0.977 \\
\hline Health care & 0.916 \\
\hline Disease prevention & 0.933 \\
\hline Health promotion & 0.946 \\
\hline
\end{tabular}




\section{Results}

Socio-demographic status and general health features of the participants are given in Table 3. The mean age of participants was calculated as $21.4 \pm 4.1$, height $165.9 \pm 7.6 \mathrm{~cm}$ and weight $61.7 \pm 11.5$ $\mathrm{kg}$. According to the answers given to the questionnaires, $87.3 \%(\mathrm{n}=48)$ of the participants were female, 96.4\% $(n=53)$ were single, $52.7 \%(n=29)$ were first year students and $45 \%(n=29)$ had a mean monthly income of between 1600 and 3000 TRY, 85.5\% $(n=47)$ of the children were in the nuclear family, and $85.5 \%(n=47)$ were living in more crowded families than in 3 , and $80 \%(n=44)$ were living in their own houses and apartments. When the students who participated in the research had a reading habit of reading books and magazines, $40 \%$ of the participants $(n=22)$ did not read any newspapers and $38.2 \%(n=21)$ read at most 5 books per year. The mean years of education of participants was calculated as $13.9 \pm 0.97$.

According to the findings of healthy living habits, $76.4 \%(n=42)$ of the participants are not on diet and $18.2 \%(n=10)$ of the participant's diet is based on their own knowledge. $92.7 \%(n=49)$ of the participants answered daily exercise habits mostly such as walking. Mean daily tea consumption of the participants was $2.73 \pm 1.94$ cups and coffee consumption was $1.04 \pm 0.86$ cups and water consumption was $4.09 \pm 3.43$ cups. Participants' health insurance was found to be covered by general health insurance at $83.6 \%(n=46)$ and $60 \%(n=36)$ of the participants' health perception as was good (Table 4).

Table 3. Socio-demographic status and general health features of the participants $(n=55)$.

\begin{tabular}{|l|l|l|l|}
\hline \multirow{3}{*}{ Gender } & & $\mathbf{N}$ & $\mathbf{\%}$ \\
\hline \multirow{3}{*}{ Marital status } & Male & 7 & 12,7 \\
\cline { 2 - 4 } & Female & 48 & 87,3 \\
\hline Year in the university & Married & 2 & 3,6 \\
\cline { 2 - 4 } & Single & 53 & 96,4 \\
\hline Years of education & First year & 29 & 52,7 \\
\cline { 2 - 4 } & Second year & 26 & 47,3 \\
\hline \multirow{5}{*}{ Income } & 13 years & 25 & 45,5 \\
\cline { 2 - 4 } & 14 years & 23 & 41,8 \\
\cline { 2 - 4 } & $15+$ years & 7 & 12,7 \\
\hline & $\leq 1600$ TRY & 10 & 18,2 \\
\cline { 2 - 4 } & 1601 TL-3000 TRY & 29 & 52,7 \\
\cline { 2 - 4 } & $3001-4500$ TRY & 10 & 18,2 \\
\cline { 2 - 4 } & 4501 TRY $\leq$ & 6 & 10,9 \\
\hline Familiy & Nuclear family & 47 & 85,5 \\
\cline { 2 - 4 } & Extended family & 7 & 12,7 \\
\cline { 2 - 4 } & Fragmented family & 1 & 1,8 \\
\hline Number of people living in the family & $\leq 3$ & 8 & 14,5 \\
\cline { 2 - 4 } & $3+$ & 47 & 85,5 \\
\hline Residential ownership & Own house & 44 & 80 \\
\cline { 2 - 4 } & Rent & 11 & 20 \\
\hline Living house features & Detached house & 11 & 20 \\
\cline { 2 - 4 } & Apartment & 44 & 80 \\
\hline & None & 22 & 40 \\
\hline
\end{tabular}




\begin{tabular}{|l|l|l|l|}
\hline Newspaper reading habit (newspaper / week) & $1-3$ & 28 & 50,9 \\
\cline { 2 - 4 } & $4-7$ & 5 & 9,1 \\
\hline \multirow{3}{*}{ Book reading habit (book/year) } & None & 2 & 3,6 \\
\cline { 2 - 4 } & $1-5$ & 21 & 38,2 \\
\cline { 2 - 4 } & $6-10$ & 13 & 23,6 \\
\cline { 2 - 4 } & $11+$ & 19 & 34,5 \\
\hline
\end{tabular}

A majority of $81.8 \%$ of respondents in the total sample indicated no alcohol consumption. In total, a majority of the respondents (65.5\%) indicated that they never smoke. The Body Mass Index (BMI) was calculated by the answers to the questions on self-assessed weight and heights included in the questionnaire. The BMI, according to the WHO classification is an index of weight for height that is commonly used to classify underweight, overweight and obesity in adults. It is defined as the weight in kilograms divided by the square of the height in metres $\left(\mathrm{kg} / \mathrm{m}^{2}\right)$. According to the analysis, it is seen that $76.4 \%(\mathrm{n}=42)$ of the participants are in normal weight (Table 4).

Table 4: Health status of the participants $(n=55)$

\begin{tabular}{|c|c|c|c|}
\hline \multirow{5}{*}{ Weight status (BMI) } & & $\mathbf{N}$ & $\%$ \\
\hline & Underweight & 5 & 9,1 \\
\hline & Normal Range & 42 & 76,4 \\
\hline & Overweight & 6 & 10,9 \\
\hline & Obese & 2 & 3,6 \\
\hline \multirow[t]{3}{*}{ Diet } & I'm not on a diet. & 42 & 76,4 \\
\hline & I follow diet given by a dietician. & 3 & 5,5 \\
\hline & I diet based on my own knowledge. & 10 & 18,2 \\
\hline \multirow{2}{*}{ Exercise } & I do not exercise & 4 & 7,3 \\
\hline & Exercise (walking, collective sports, swimming, pilates, & 49 & 92,7 \\
\hline \multirow{3}{*}{ Smoking } & I'm smoking now. & 17 & 30,9 \\
\hline & I was smoking earlier, but I quit. & 2 & 3,6 \\
\hline & I never smoked. & 36 & 65,5 \\
\hline \multirow[t]{2}{*}{ Alcohol } & No & 45 & 81,8 \\
\hline & Yes & 10 & 18,1 \\
\hline \multirow[t]{5}{*}{ Health insurance } & General Health Insurance & 46 & 83,6 \\
\hline & General Health Insurance and Private Insurance & 1 & 1,8 \\
\hline & Private insurance & 1 & 1,8 \\
\hline & Neither & 2 & 3,6 \\
\hline & Not know & 5 & 9,1 \\
\hline \multirow{4}{*}{ Health status } & Very good & 11 & 18,3 \\
\hline & Good & 36 & 60,0 \\
\hline & Normal & 12 & 20,0 \\
\hline & Bad & 1 & 1,7 \\
\hline
\end{tabular}

Findings of participants' health literacy and sub-literacy index scores were given in Table 5. While the general health literacy index score of the students who answered the questionnaire was $33.9 \pm 7.42(\mathrm{n}=55)$. The means and standard deviations of the indices are varied by sub-index. The highest means is calculated the health promotion $(\mathrm{X}=34.4 \pm 8.34)$ and then the healthcare $(\mathrm{X}=34.2 \pm 6.89)$ and then disease prevention $(\mathrm{X}=33.1 \pm 8.92)$. 
Table 5: Means of the health literacy indices $(n=55)$.

\begin{tabular}{|l|l|l|}
\hline & $\mathbf{X}$ & SD \\
\hline General & 33.9 & 7.42 \\
\hline Health Care & 34.2 & 6.89 \\
\hline Disease Prevention & 33.1 & 8.92 \\
\hline Health Promotion & 34.4 & 8.34 \\
\hline
\end{tabular}

COMPARING GENERAL HEALTH LITERACY INDEX SCORES

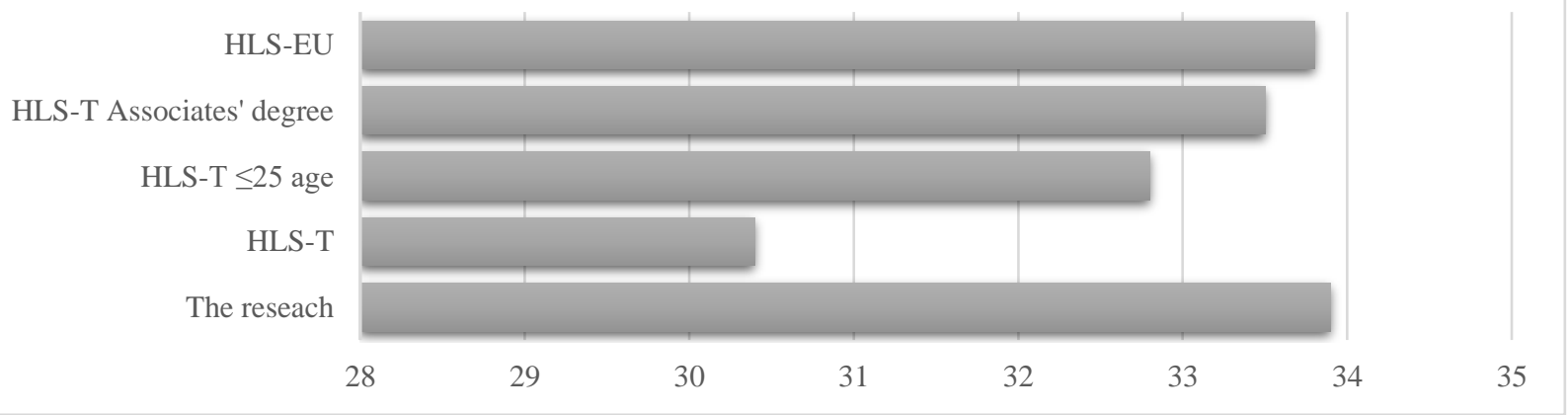

Figure 1: Comparing the research general health literacy index scores with HLS-T-Q and HLSEU-Q index scores.

The study showed that (Figure 1) HLS index was above the average of the health literacy scale (HLS-T) made using Turkey's (Durusu-Tanriöver, 2014) general population (30.4), where the individuals were 25 years of age (32.8) and with associate degree education (33.5).

Table 6: Compare results of the present study, HLS-T-Q and HLS-EU-Q for the prevelance of the general HL $(\mathrm{n}=55)$.

\begin{tabular}{|l|l|l|l|}
\hline Health Literacy & Results of the present study (\%) & HLS-T-Q (\%) & HLS-EU-Q (\%) \\
\hline Inadequate & 7,3 & 24,5 & 12,4 \\
\hline Problematic & 34,5 & 40,1 & 35,2 \\
\hline Sufficient & 41,8 & 27,8 & 36,0 \\
\hline Excellent & 16,4 & 7,6 & 16,5 \\
\hline
\end{tabular}

According to the categorized health literacy, it was seen that $41.8 \%$ of the participants were 'sufficient' and 16.4\% of them were in the level of 'excellent' health literacy (Table 6 and Figure 2). Correlation analysis revealed a positive statistically significant relationship between age and general health literacy $(r=0.272, p \leq 0.05)$. When the relationship between the participants' first and second grades and the general health literacy status was examined, 69.6\% $(n=16)$ of the participants with inadequate or problematic health literacy were of the first grade, $59.4 \%(n=19)$ were of the second grade students. This result shows that there is a meaningful relationship between the grade of the students and their level of general health literacy $(\mathrm{x} 2=4.496, \mathrm{df}=1$, $\mathrm{p} \leq 0.05)$. 


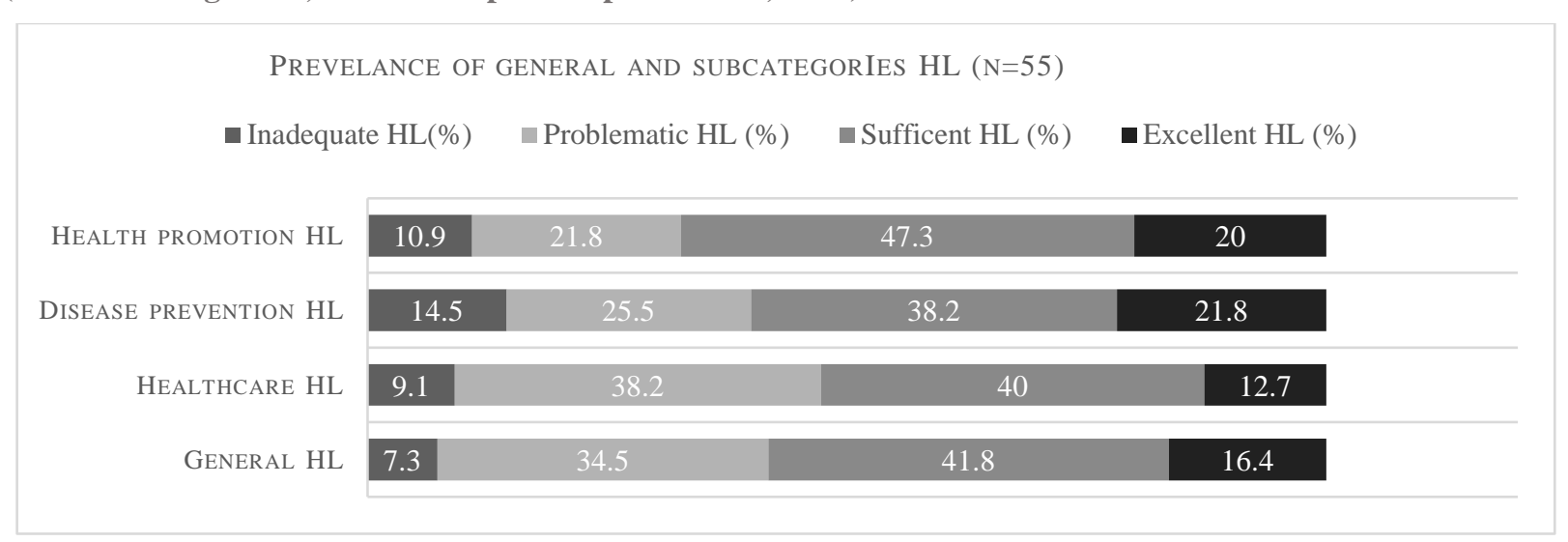

Figure 2: Prevelance of general and subcategories HL ( $n=55)$

\section{Discussions}

This research aims to describe the health literacy level of medical secretary students as health worker candidates. According to the results of the research, the average age of participants is 21.4 years. According to sociodemographic characteristics they are mostly single, living in minimum living conditions, generally not having any health problems, and participating in medical secretarial training for at least one year.

The average educational year of the participants is 13.9 years. According to UNESCO in overall literacy in Turkey for 15-24 years old male was $99.81 \%$, for female $99.17 \%$, and $99.49 \%$ was in total (UNESCO, 2018). The effective variable in calculating the human development index of a country is the average year of education. According to the UNDP, it was increased from 1980 to 2012 in Turkey (from 2.9 to 6.5) although not at the desired level (12.9 years) (Malik, 2013).

In this study, the HLS-EU-Q was used and shown to be a valid tool to provide comprehensive measurement. The participants' overall health literacy averages were $33.9 \pm 7.42$. This finding health literacy scale (HLS-T) made using Turkey's (Durusu-Tanriöver, 2014) general population compared with the results of the study (30.4), 25 years of age (32.8) and associate degree education (33.5) were above average.

The findings were found to be consistent with the results of a similar study, including 8 different European countries (33.8 \pm 8 years) (see Figure 1$)$. When we look at the sub-indices, it is seen that the index of health promotion, health care, and disease prevention index is above the general health literacy average.

The health literacy is not independent of general literacy skills at population or subpopulation (Rudd, 2007). This relationship between general literacy and health literacy (Sørensen et al., 2012; von Wagner et al., 2007) has proven to the work well beyond the country average for the duration of schooling and the health literacy average. The results are close to or even above to those of other research findings, in terms of age and educational level, and this can be explained by the fact that there is also a training curriculum for health services in addition to administrative services education in medical secretarial training. 
The research which including 1222 people who work in primary health care services, is one of the few researches on the healthcare workers' health literacy levels (Deniz et al., 2018). According to this research, which was conducted after in-service training on the primary care health services, the average of health literacy is $37.58 \pm 7.49$ for the age group of between 21 and 25 years, and for which the assistant health worker and the associate degree education were 35.0 \pm 7.24 . Although they appear to be similar groups to those in our study, the participants were working as health personnel in that study. Therefore, the participants of the current study who are still students have the lower overall health literacy than those employed as health workers. It can be argued that the employed participants with higher overall health literacy level can be due to both their professional experience and the support of in-service training they have attended.

When the general health literacy index was categorized, it was determined that $64.6 \%$ of the Turkish population were in the 'inadequate' $(24.5 \%)$ or 'problematic' $(40.1 \%)$ health literacy categories (Durusu-Tanriöver, 2014). In our study, it was seen that $41.8 \%$ of the participants were 'sufficient' and $16.4 \%$ of them were in the level of 'excellent' health literacy. These results also indicate that health literacy levels are in good condition according to the general population of the participants.

Another finding is the positive relationship between age and general health literacy. The fact that participants are in the age range of 21-25 years is in accordance with the literature that this age group has higher health literacy than other age groups. In almost all studies of health literacy in Europe, (Sørensen et al., 2015; von Wagner et al., 2007) America, (Kirsch, 1993; Rudd, 2007) Asia (Duong et al., 2017) and Turkey (Deniz et al., 2018; Durusu-Tanröver, 2014; Güven et al., 2018) this age range is at higher literacy level than the general population.

According to researches, the lowness of health literacy can cause on the one hand the bad health results such as the weak doctor-patient relationship, increasing in hospitalization, applying to hospital again in 30 days, consulting to emergency room and disease, and death rates, on the other hand, it can cause be decreasing in mammography usage, vaccination, cancer screening, and proper drug usage rates (Baker, 2006; Berkman et al., 2004; Berkman, Sheridan, Donahue, Halpern, \& Crotty, 2011; Berkman, Sheridan, Donahue, Halpern, Viera, et al., 2011; Davis, Williams, Marin, Parker, \& Glass, 2002; Kripalani et al., 2010; Mitchell et al., 2012; Raynor, 2012; Rudd et al., 1999; Sørensen et al., 2012; Williams, Davis, Parker, \& Weiss, 2002).

Health literacy is a dynamic product of the interactions between individuals, patients, employees, organizations, and systems (Naccarella, Wraight, \& Gorman, 2016). On one hand, health literacy is influenced by aspects of the health care system at the population level (Sørensen et al., 2012) which reflects the enormous complexity in the delivery of effective healthcare and quality health outcomes (Rasu et al., 2015; Sørensen et al., 2012).

\section{Conclusions and Recommendations}

In this study, it was found that approximately $70 \%$ of the 55 associate medical secretarial students studying at Ankara University in 2018 and volunteering to participate in the research have sufficient health literacy. It is very important that this group, working as a secretary and patient 
guidance personnel in the production of health services in the health sector, has health literacy in order to facilitate their own health and access to the health services of the patients they serve.

Health literacy can't be considered independent of the general literacy level. In the ever-changing and developing world, it is necessary to earn the awareness of lifelong learning for individuals to become general and health literate. In this process, it is important that individuals support themselves in their own efforts and in school and business life. It should not be forgotten that the individuals in associate degree education are a special group in between the age group of adolescents and adults and should be supported in terms of individual development and awareness period. This is why, besides vocational education (knowledge, skills and attitude) at associate degree level, it is necessary to support with life-long education consciousness, general culture (acquiring habits such as newspaper and book reading, attending to cinema, theater, concert, exhibition), healthy life behaviors, education given at school is important in bringing positive behaviors in development. It is recommended that health literacy training should be added to the curriculum so that issues related to health literacy are acquired at the level of knowledge, skills and attitudes. In addition, individual development should be encouraged by encouraging students to participate in social, cultural and artistic activities in elective courses and extracurricular times outside professional courses.

Developmental education support for health literacy in formal and in-service training should be provided for all employees who are directly or indirectly involved in the production of health services, not just medical secretaries. It is suggested that managers of health institutions should give the in-service training of healthcare literacy training full play, especially for the administrative service class.

Our research has been limited to a specific group and limited participants, and it is not possible to generalize the results. However, to our knowledge, this is the first study with medical secretaries and may provide expected significant contribution to the literature to some extent. Similar comparable research can be done in terms of other health professionals, and it will facilitate the determination of the level of health literacy and training needs according to occupational groups.

\section{References}

[1] Adams, R. J., Appleton, S. L., Hill, C. L., Dodd, M., Findlay, C., \& Wilson, D. H. (2009). Risks associated with low functional health literacy in an Australian population. Medical Journal of Australia, 191(10), 530.

[2] Baker, D. W. (2006). The meaning and the measure of health literacy. Journal of general internal medicine, 21(8), 878-883.

[3] Batterham, R., Hawkins, M., Collins, P., Buchbinder, R., \& Osborne, R. (2016). Health literacy: applying current concepts to improve health services and reduce health inequalities. Public Health, 132, 3-12.

[4] Berkman, N. D., Davis, T. C., \& McCormack, L. (2010). Health literacy: what is it? Journal of health communication, 15(S2), 9-19.

[5] Berkman, N. D., DeWalt, D. A., Pignone, M., Sheridan, S. L., Lohr, K. N., Lux, L., . . Arthur, J. (2004). Literacy and health outcomes. Evidence report/technology assessment No. 87.

[6] Berkman, N. D., Sheridan, S. L., Donahue, K. E., Halpern, D. J., \& Crotty, K. (2011). Low health literacy and health outcomes: an updated systematic review. Annals of internal medicine, 155(2), 97-107. 
[7] Berkman, N. D., Sheridan, S. L., Donahue, K. E., Halpern, D. J., Viera, A., Crotty, K., .. . Harden, E. (2011). Health literacy interventions and outcomes: an updated systematic review. Evid Rep Technol Assess (Full Rep), 199(1), 941.

[8] Bush, R. A., Boyle, F. M., \& Ostini, R. (2010). Risks associated with low functional health literacy in an Australian population. The Medical Journal of Australia, 192(8), 478-479.

[9] Coleman, C. (2011). Teaching health care professionals about health literacy: A review of the literature. Nursing Outlook, 59(2), 70-78.

[10] Consortium, H.-E. (2012). Comparative report of health literacy in eight EU member states. The European health literacy survey HLS-EU.

[11] Cortina, J. M. (1993). What is coefficient alpha? An examination of theory and applications. Journal of applied psychology, 78(1), 98.

[12] CSDH. (2008). Closing the gap in a generation: Health equity through action on the social determinants of health. Geneva: World Health Organization Retrieved from

http://www.who.int/social_determinants/thecommission/finalreport/en/index.html., Date of Access: 12.06 .2018

[13] Davis, T. C., Williams, M. V., Marin, E., Parker, R. M., \& Glass, J. (2002). Health literacy and cancer communication. CA: a cancer journal for clinicians, 52(3), 134-149.

[14] Deniz, S., Öztaş, D., \& Akbaba, M. (2018). Determining the level of health literacy and affecting factors of health professionals working in primary health care services. Sakarya Tip Dergisi, 8(2), 214-228.

[15] Duong, T. V., Aringazina, A., Baisunova, G., Pham, T. V., Pham, K. M., Truong, T. Q., ... Su, T. T. (2017). Measuring health literacy in Asia: Validation of the HLS-EU-Q47 survey tool in six Asian countries. Journal of epidemiology, 27(2), 80-86.

[16] Durusu-Tanrı̈̈ver, M. (2014). Yıldırım HH. Demiray-Ready FN, Çakır, B. ve Akalın HE, Türkiye Sağlık Okuryazarlığı Araştırması, Birinci Baskı, Sağlık-Sen Yayınları, Ankara.

[17] Güven, D. Y., Bulut, H., \& Öztürk, S. (2018). Sağlık Bilimleri Fakültesi Öğrencilerinin Sağlık Okuryazarlığ Düzeylerinin İncelenmesi/Examining the Health Literacy Levels of Health Sciences Faculty Students. Journal of History Culture and Art Research, 7(2), 400-409.

[18] Haun, J. N., Valerio, M. A., McCormack, L. A., Sørensen, K., \& Paasche-Orlow, M. K. (2014). Health literacy measurement: an inventory and descriptive summary of 51 instruments. Journal of health communication, 19(sup2), 302-333.

[19] İlgün, G., Turaç, İ. S., \& Orak, S. (2015). Health literacy. Procedia-Social and Behavioral Sciences, 174, 2629-2633.

[20] Kahraman, Ç., Karagöz, Y., Yalman, F., \& Yusuf, Ö. (2018). Sağlık Okuryazarlığının Hasta Memnuniyeti Üzerine Etkisi. Ekonomik ve Sosyal Araştırmalar Dergisi.

[21] Kirsch, I. S. (1993). Adult literacy in America: A first look at the results of the National Adult Literacy Survey: ERIC.

[22] Kripalani, S., Jacobson, T. A., Mugalla, I. C., Cawthon, C. R., Niesner, K. J., \& Vaccarino, V. (2010). Health literacy and the quality of physician-patient communication during hospitalization. Journal of Hospital Medicine, 5(5), 269-275.

[23] Kutner, M., Greenberg, E., Jin, Y., Boyle, B., Hsu, Y.-c., \& Dunleavy, E. (2007). Literacy in Everyday Life: Results from the 2003 National Assessment of Adult Literacy. NCES 2007-490. National Center for Education Statistics.

[24] Kutner, M., Greenburg, E., Jin, Y., \& Paulsen, C. (2006). The Health Literacy of America's Adults: Results from the 2003 National Assessment of Adult Literacy. NCES 2006-483. National Center for Education Statistics.

[25] Lloyd, J., Thomas, L., Powell-Davies, G., Osten, R., \& Harris, M. (2018). How can communities and organisations improve their health literacy? Public health research \& practice, 28(2).

[26] Malik, K. (2013). Human development report 2013. The rise of the South: Human progress in a diverse world. 
[27] Mitchell, S. E., Sadikova, E., Jack, B. W., \& Paasche-Orlow, M. K. (2012). Health literacy and 30day postdischarge hospital utilization. Journal of health communication, 17(sup3), 325-338.

[28] Naccarella, L., Wraight, B., \& Gorman, D. (2016). Is health workforce planning recognising the dynamic interplay between health literacy at an individual, organisation and system level? Australian Health Review, 40(1), 33-35.

[29] Nutbeam, D. (2008). The evolving concept of health literacy. Social Science \& Medicine, 67(12), 2072-2078.

[30] Paasche-Orlow, M. K., \& Wolf, M. S. (2007). The causal pathways linking health literacy to health outcomes. American journal of health behavior, 31(1), S19-S26.

[31] Parker, R. M., Baker, D. W., Williams, M. V., \& Nurss, J. R. (1995). The test of functional health literacy in adults. Journal of general internal medicine, 10(10), 537-541.

[32] Rasu, R. S., Bawa, W. A., Suminski, R., Snella, K., \& Warady, B. (2015). Health literacy impact on national healthcare utilization and expenditure. International journal of health policy and management, 4(11), 747.

[33] Raynor, D. T. (2012). Health literacy: British Medical Journal Publishing Group.

[34] Rudd, R. E. (2007). Health literacy skills of US adults. American journal of health behavior, 31(1), S8-S18.

[35] Rudd, R. E. (2015a). The evolving concept of health literacy: new directions for health literacy studies. Journal of Communication in Healthcare, 8(1), 7-9. doi:10.1179/1753806815Z.000000000105

[36] Rudd, R. E. (2015b). The evolving concept of health literacy: new directions for health literacy studies: Taylor \& Francis.

[37] Rudd, R. E., Moeykens, B. A., \& Colton, T. C. (1999). Health and literacy: a review of medical and public health literature. Office of Educational Research and Improvement.

[38] Sørensen, K., Pelikan, J. M., Röthlin, F., Ganahl, K., Slonska, Z., Doyle, G., . . Uiters, E. (2015). Health literacy in Europe: comparative results of the European health literacy survey (HLS-EU). European journal of public health, 25(6), 1053-1058.

[39] Sørensen, K., Van den Broucke, S., Fullam, J., Doyle, G., Pelikan, J., Slonska, Z., \& Brand, H. (2012). Health literacy and public health: a systematic review and integration of definitions and models. Bmc Public Health, 12(1), 80.

[40] Sørensen, K., Van den Broucke, S., Pelikan, J. M., Fullam, J., Doyle, G., Slonska, Z., . . . Brand, H. (2013). Measuring health literacy in populations: illuminating the design and development process of the European Health Literacy Survey Questionnaire (HLS-EU-Q). Bmc Public Health, 13(1), 948.

[41] Tabachnick, B. G., \& Fidell, L. S. (2007). Using multivariate statistics: Allyn \& Bacon/Pearson Education.

[42] Turkoglu, A. R., Demirci, H., Coban, S., Guzelsoy, M., Toprak, E., Aydos, M. M., . . Ustundag, Y. (2018). Evaluation of the relationship between compliance with the follow-up and treatment protocol and health literacy in bladder tumor patients. The Aging Male, 1-6.

[43] UNESCO. (2018). Country Profile:Turkey. Retrieved from: http://uis.unesco.org/en/country/TR, Date of Access: 20.06.2018

[44] Von Wagner, C., Knight, K., Steptoe, A., \& Wardle, J. (2007). Functional health literacy and health-promoting behaviour in a national sample of British adults. Journal of Epidemiology \& Community Health, 61(12), 1086-1090.

[45] Von Wagner, C., Steptoe, A., Wolf, M. S., \& Wardle, J. (2009). Health literacy and health actions: a review and a framework from health psychology. Health Education \& Behavior, 36(5), 860-877.

[46] Wallston, K. A., Cawthon, C., McNaughton, C. D., Rothman, R. L., Osborn, C. Y., \& Kripalani, S. (2014). Psychometric properties of the brief health literacy screen in clinical practice. Journal of general internal medicine, 29(1), 119-126.

[47] Williams, M. V., Davis, T., Parker, R. M., \& Weiss, B. D. (2002). The role of health literacy in patient-physician communication. Family Medicine-Kansas City-, 34(5), 383-389. 
[48] Yuen, E. Y., Knight, T., Ricciardelli, L. A., \& Burney, S. (2018). Health literacy of caregivers of adult care recipients: A systematic scoping review. Health \& social care in the community, 26(2), e191-e206.

*Corresponding author.

E-mail address: ptekin@ ankara.edu.tr 